\title{
BIOPOLÍTICA, SOBERANÍA Y DECONSTRUCCIÓN
}

\author{
BIOPOLITICS, SOVEREIGNTY AND DECONSTRUCTION
}

\author{
Emmanuel Biset ${ }^{1}$ \\ CONICET y Universidad Nacional de Córdoba (Argentina)
}

Recibido: 02/12/2016

Aceptado: 07/03/2017

Resumen: El objetivo del presente artículo es precisar algunos desplazamientos en la biopolítica desde textos de Jacques Derrida. Para ello, en primer lugar, se establece un marco de comprensión de la categoría de biopolítica y se muestra la diferencia entre Foucault y Derrida al respecto. En segundo lugar, se muestran los desplazamientos que produce Derrida: un cuestionamiento a la epocalización, una deconstrucción de la biopolítica negativa (al mostrar el nexo con la soberanía) y una deconstrucción de la biopolítica afirmativa (al mostrar el nexo constitutivo entre vida y muerte). Todo esto en vistas a pensar dos modos diferentes del pensamiento político contemporáneo.

Palabras clave: Biopolítica, Foucault, Derrida.

\begin{abstract}
The aim of this paper is to explain some biopolitic's shifts in texts by Jacques Derrida. In order to do this, first it is established a framework of understanding of the category of biopolitics and the difference between Foucault and Derrida about it. Secondly, it is shown the displacements produced by Derrida: a critique to the historical periodization, a deconstruction of negative biopolitics (showing the link to sovereignty) and a deconstruction of affirmative biopolitics (showing the constitutive link between life and death). This is all to say that there are two different ways to think of contemporary political thought.
\end{abstract}

Key-words: Biopolitics, Foucault, Derrida.

1. (biseticos@gmail.com) Emmanuel Biset es Investigador del CONICET y Profesor de la Universidad Nacional de Córdoba (Argentina). Director del Programa de Estudios en Teoría Política (CIECS - UNC y CONICET). Miembro del Comité Editor de NOMBRES. Revista de Filosofía. Ha publicado los libros: Violencia, justicia y política. Una lectura de Jacques Derrida (Eduvim, 2012), El signo y la hiedra. Escritos sobre Jacques Derrida (Alción, 2013) y compilado: Derrida político (Colihue, 2013), Sujeto. Una categoría en disputa (La Cebra, 2015) y Estado. Perspectivas posfundacionales (Prometeo, 2017). 
El abismo, si lo hay, es que haya más de un suelo, más de un sólido, y más de un único umbral.

J.D.

\section{Introducción}

Introducirse en el amplio mapa de los debates en torno a la biopolítica en el mundo contemporáneo supone algunas precisiones en torno al punto de partida. Como supo señalar R. Esposito existen por lo menos dos tradiciones al respecto: una amplia que puede remontarse hasta $\mathrm{K}$. Binding y otra más específica circunscripta al nombre de M. Foucault ${ }^{2}$. Aquí vamos a partir de la segunda tradición, pero desde una perspectiva singular: abordar el estatuto de la cuestión biopolítica en los marcos del pensamiento político contemporáneo. Con el término «estatuto» no me refiero a una indagación en torno a su legitimidad ontológica o epistemológica, sino al modo en que se trabaja eso llamado pensamiento político. Esto es, cómo pensar este debate más allá de la hermenéutica de un autor o de una tradición particular. En este sentido, más allá de la adopción de un lenguaje o una gramática específica pensar la biopolítica en un registro más amplio. Si se quiere, se trata de pensar qué supone este debate como reformulación del pensamiento político y, por ende, qué desafíos presenta en términos metodológicos y teóricos.

Para ello, de modo provisorio, quisiera partir de un esquema nietzscheano para precisar un posible acercamiento a eso denominado pensamiento político contemporáneo ${ }^{3}$. Primero, para señalar que la política no es sino una X cuyo significado es, a priori, indefinible (o, como señala Derrida, que el concepto de lo político es inadecuado por definición a sí mismo ${ }^{4}$. Segundo, que esa X no denota un vacío, sino una serie de sedimentaciones no conclusivas, es decir, un ejército de metáforas y metonimias que nunca agotan el sentido de eso llamado política. Tercero, que se trata de pensar

2. Esposito, R.: Bios. Buenos Aires: Amorrortu, 2006.

3. Utilizo la expresión "pensamiento político» de un modo amplio para evitar la discusión entre "filosofía política» o "teoría política». Utilizo el nombre de Nietzsche solo a título indicativo siguiendo el esquema de su texto "Verdad y mentira en un sentido extramoral". Cf. Nietzsche, F.: Sobre verdad y mentira en sentido extramoral. Madrid: Tecnos, 2007.

4. Derrida, J.: Políticas de la amistad. Madrid: Trotta, 1998.

Thémata. Revista de Filosofía N56 (2017) pp.: 285-303. 
no sólo lenguajes enfrentados entre sí, sino que los lenguajes políticos no son sino modos de delimitar un significado de política. He allí un problema específico a abordar: la doble relación entre disputas internas a una configuración de sentido y modos de nombrar radicalmente diversos. Todo esto para señalar que si emulamos la pregunta de A. Badiou respecto de N. Sarkozy, es decir, de qué es el nombre M. Foucault como genealogía de una corriente específica del debate biopolítico, me atrevería a decir dos cosas: de un lado, que es el nombre de la crisis radical del lenguaje político que supo hegemonizar un sentido de la política por algo más de tres siglos. Cuando uso la expresión «lenguaje político» me refiero a la conjunción de un entramado institucional y un vocabulario específico ${ }^{5}$. De otro lado, es el intento posiblemente más radical de ensayar lenguajes que excedan esa crisis. Como es ya reconocido, se pueden situar por lo menos tres en M. Foucault: el de la disciplina, el de la biopolítica y el de la gubernamentalidad.

De modo que se trata de una desestabilización extrema de la política entendida desde la retórica de la soberanía al mismo tiempo que el ensayo de nuevos lenguajes para trabajar entramados institucionales y vocabularios específicos. Se sabe que desde su mismo planteo, esto presenta un doble desafío. Ante todo, se trata de pensar cuál es la relación entre estos lenguajes desde la misma vacilación foucaultiana al respecto (o bien como lenguajes sucesivos, o bien como lenguajes correlativos). Diría que el desafío se encuentra en evitar la postulación de un lenguaje general que comprenda los distintos lenguajes políticos y un particularismo de las lenguas singulares (si se quiere, pensar en los términos de una topología de la sobredeterminación). Luego, se encuentra el desafío del mismo lugar de intervención de M. Foucault, algo que fue una preocupación constante en sus textos, desde las reformulaciones metodológicas a la postulación de una ontología crítica del presente. Me interesa pensar este doble desafío desde una categoría próxima a M. Foucault, aunque de una extensión que lo excede: la diferencia. Puesto que se trata de pensar el carácter diferencial de los diversos lenguajes políticos, al mismo tiempo que una escritura

5. La adopción de la expresión «lenguaje político» se inscribe en las discusiones sobre historia de los discursos o de los conceptos políticos. De hecho, E. Palti propone utilizar esta expresión para recuperar los aportes de diversas tradiciones: la Escuela de Cambridge (Q. Skinner, J. Pocock), la Begriffgeschichte (R. Koselleck, O. Brunner) y ciertas corrientes francesas e italianas (P. Rosanvallon, G. Duso). De todos modos, no recurro a esta expresión para inscribir el texto en la perspectiva historicista sino simplemente para señalar que eso denominado política circunscribe su sentido desde una serie de lenguajes, conceptos, gramáticas contingentes siempre tramados en instituciones. Cf. Palti, E.J.: "Temporalidad y refutabilidad de los conceptos políticos", Prismas 9 (2005).

Thémata. Revista de Filosofía №56 (2017) pp.: 285-303. 
que asume explícitamente su carácter diferente respecto a los modos habituales de ejercer la filosofía.

En este marco general, este artículo presenta algunas precisiones sobre la relación de la deconstrucción con el debate biopolítico. Por ello me interesa aquí precisar algunos aspectos del modo en que J. Derrida se inscribe en eso denominado biopolítica, no en vistas a indagar qué autor efectúa un aporte más significativo, sino para volver sobre la indagación inicial, esto es, cómo comprender estos elementos en su inscripción en el pensamiento político contemporáneo. Para situar esta aproximación, en primer lugar, voy a precisar un marco general del debate entre M. Foucault y J. Derrida desde dos aspectos: mostrando cómo se trata de dos gramáticas del pensamiento político y dos modos de entender la diferencia. En segundo lugar, me voy a detener en la deconstrucción de la biopolítica negativa y de la biopolítica afirmativa ${ }^{6}$. Con ello me refiero a que la perspectiva de Derrida no sólo se dirige a cuestionar el mismo modo de construir la perspectiva biopolítica, sino que cuestiona algunas de las posiciones actuales que encuentran una especie de salida política en cierto vitalismo (que sigue trabajando con un concepto demasiado simple de vida).

En resumidas cuentas, el artículo busca mostrar cómo J. Derrida cuestiona la misma noción de biopolítica, es decir, que su esfuerzo teórico se dirige a mostrar sus límites a la hora de comprender no sólo la política contemporánea, sino ciertas formas del discurso filosófico. Se trata, en resumidas cuentas, de un modo de trabajo filosófico que se pregunta por las nociones de vida y política inscriptas en la categoría de biopolítica ${ }^{7}$. Y ello no para descartar la aventura de la mirada foucaultiana, sino para tramar su significado desde una diferencia cuyos límites no se pueden fijar fácilmente. Todo esto puede ser sintetizado con la construcción de un significante en J. Derrida: biotanatopolítica.

\section{Dos gramáticas políticas}

Antes de indagar la cuestión de la biopolítica es necesario atender a los modos de entender la categoría de diferencia en M. Foucault y J. Derrida. Que no son sino formas de comprender el ejercicio de la filosofía. Para situar estos dos modos me interesa partir de su ya conocido debate.

\section{Esposito, R.: Bios cit.}

7. Timothy Campbell y Adam Sitze señalan cuatro impasses al pensar la biopolítica como las relaciones entre vida y política: Species living, the power of life, the new millennial animal y the resolution to live. Se trata de mostrar en cada uno de estos aspectos cómo se abren una serie de preguntas que el mismo Foucault no responde. Cf. Campbell, T. y Sitze, A. (ed.): Biopolitics: A reader. Durham-Londres: Duke University Press, 2013. 
Entiendo que allí se juegan dos modos de entender el trabajo con la filosofía que asume la necesidad de romper con su forma tradicional y por ende la politicidad constitutiva de su apuesta. Para decirlo de otro modo, ese debate permite entender el trabajo sobre el legado del pensamiento francés de los 60. Pues bien, diría que en M. Foucault existe un modo de trabajar la diferencia como afuera, o mejor, los modos en que ese afuera permite desplazar la filosofía ${ }^{8}$. La atención a las prácticas, a los discursos marginales, a la erudición inútil y a los saberes soterrados, conlleva un gesto que no sólo hace de la filosofía un discurso específico y limitado, sino que diseña una práctica teórica que muestra la región media que configura la historicidad de lo que somos atendiendo a fronteras de exclusión. Diría que en Derrida la diferencia es trabajada de otro modo desde que el problema es cómo dar lugar a una escritura que desplace desde el interior el discurso filosófico, y así una práctica teórica que reconoce el afuera como imposible y por ello apuesta por la deconstrucción de una lengua heredada?

Ahora bien, estos modos de entender la filosofía no sólo dan lugar a formas de la filosofía, o modos de ejercer la sospecha diversos, sino que están atravesados por lo que denominaría dos pulsiones diversas. En el caso de M. Foucault, la diferencia se encuentra atravesada por una pulsión analítica, y con ello me refiero no tanto a la recurrencia a clasificaciones, denominaciones, sino a la fijación del límite como algo indivisible. Como supo señalar J. Derrida, por tomar un solo caso, M. Foucault al mismo tiempo que muestra el carácter proteico del poder, que multiplica sus modos, no lo deja de nombrarlo en singular ${ }^{10}$. En el caso de J. Derrida, la diferencia se encuentra atravesada por una pulsión de huella, y con ello me refiero no a la recurrencia del problema de la différance, sino a un modo de trabajar el límite que conlleva como primer paso pensar su divisibilidad. Como supo señalar M. Foucault, al mismo tiempo que muestra el carácter metafísico de la filosofía, no deja de trabajar en su interior, mos-

8. Cf. Foucault, M.: El pensamiento del afuera. Valencia: Pre-Textos, 1997.

9. Cf. J. Derrida, "La différance" en Márgenes de la filosofía. Madrid: Cátedra, 1994.

10. Escribe Derrida: «Esta pregunta, la vemos quizás perfilarse en La voluntad de saber (primer volumen de la Historia de la sexualidad). Es una pregunta singular, o más bien la cuestión de la singularidad del poder, de el poder. ¿Qué ocurre cuando hablamos del poder en singular, cuando continuamos diciendo el poder cuando, y este es uno de los motivos más originales e insistentes en Foucault, no hay poder central, capital, hegemónico, monárquico, sino una multiplicidad de poderes, redes, o un "haz de relaciones de poder" (p. 42), o "técnicas polimórficas de poderes" (p. 20)? [...] La cuestión parece clásica y filosófica en su forma. Se refiere al derecho de llamar con el mismo nombre a una multiplicidad de instancias de las cuales se subraya la irreductible multiplicidad y la heterogeneidad en cuanto a la determinación esencialmente política que se acuerda generalmente a la problemática del poder». Derrida, J.: "Au-delà du principe du pouvoir" en Revista Rue Descartes º 82, 2014.

Thémata. Revista de Filosofía $\mathrm{N}^{\circ} 56$ (2017) pp.: 285-303. 
trando su diferenciación interna ${ }^{11}$. En resumidas cuentas, se juegan aquí dos estrategias: asumiendo el carácter limitado y constreñido a jerarquías del discurso filosófico, o bien su ruptura se encuentra en la apertura a un afuera de otras prácticas y saberes, o bien su ruptura se encuentra en un trabajo minucioso que repliega la filosofía sobre sí mostrando sus inconsistencias (posiblemente una tercera estrategia surja con G. Deleuze, donde la diferencia que irrumpe da lugar a una filosofía cuyo acento recae en la invención conceptual).

En esta diferencia encuentro, a su vez, formas del pensamiento político que supondrán modos de entender la biopolítica. Puesto que si en ambos casos se asume que existe una politicidad inherente al ejercicio de la filosofía, en un caso el pensamiento político se articula en torno a las nociones de poder y liberad, o mejor, en cómo un análisis de los modos históricos en que las relaciones de poder-gobierno nos constituyen pueden dar lugar a prácticas de libertad; en el otro el pensamiento político se articula en torno a las nociones de violencia y justicia, o mejor, en cómo un análisis de la economía de la violencia irreductible puede dar lugar a la justicia como apertura incondicionada a lo que viene. Poder-libertad y violencia-justicia no son sólo temáticas o conceptos diversos, sino prácticas teórico-políticas diversas: o bien asumir que el desafío del pensamiento político consiste en indagar la metamorfosis contemporánea de las formas de poder o gobierno para dar cuenta de eso que somos, o bien asumir que el desafío pasa por trabajar los lenguajes políticos heredados, socavando su jerarquías y abriendo sin cesar a lo que viene.

Me interesa leer ambas posiciones como preguntas actuales del pensamiento político. Del lado de Derrida, asumir que no existe un afuera simple del discurso filosófico, pues de lo que se trata es de pensar cómo los procesos de significación se encuentran atravesados por jerarquías, dicotomías, dualismos, constitutivos de esa tradición llamada filosofía (por lo que, como supo insistir, el sueño de un afuera puro de la filosofía -el empirisimo- no es sino un sueño filosófico). Del lado de Foucault, asumir no sólo el desafío de una escucha atenta a los procesos políticos contemporáneos (a prácticas, institu-

11. Escribe Foucault: «...inatención por lo que los intérpretes clásicos han perdido, antes de Derrida y como él, ese pasaje de Descartes. Es por sistema. Sistema cuyo representante más decisivo es hoy Derrida, en su último brillo: reducción de las prácticas discursivas a las trazas textuales; elisión de los acontecimientos que se producen allí para no conservar más que las marcas por una lectura; invención de voces detrás de los textos para no tener que analizar los modos de implicación del sujeto en los discursos; asignación de lo originario como dicho y no dicho en el texto para no remplazar las prácticas discursivas en el campo de las transformaciones en que se efectúan. No diré que es una metafísica, la metafísica, o su recinto que se oculta en esta "textualización" de las prácticas discursivas. Iré mucho más lejos: diré que es una pequeña pedagogía históricamente bien determinada que, de manera muy visible, se manifiesta». Foucault, M.: Historia de la locura, Buenos Aires: FCE, 1998 p. 371.

Thémata. Revista de Filosofía N56 (2017) pp.: 285-303. 
ciones, relaciones, etc.), sino que la forma del discurso filosófico no se traduce de modo lineal en instituciones o prácticas, es decir, que se debe atender los modos de mediación que requieren un análisis específico para mostrar cómo operan ciertas jerarquías o dicotomías filosóficas.

Analizando la noción de diferencia no se trata de construir una perspectiva comprensiva que tome los aportes de uno y otro para postular una posición superadora. Por el contrario, se trata de atender a los diferendos entre los autores. En este sentido, desde su temprana lectura de la Historia de la locura en la época clásica, J. Derrida se pregunta por el estatuto de un lenguaje, y un modo de trabajo, que pretende exceder la razón -y así la razón filosófica. Esto conlleva a su vez un debate sobre la historia, o si se quiere sobre la historicidad de la filosofía ${ }^{12}$. El problema para Derrida no se ubica sólo en el estatuto de un discurso que pretende exceder la forma del discurso filosófico, y así un pensamiento de la diferencia cuasi-trascendental que es condición de la historicidad, sino en esa pulsión analítica que en Foucault como en muchas perspectivas actuales se traduce en una epocalización. Se trata de discutir dos presupuestos al respecto: de un lado, la misma noción de época, que Derrida discutiendo a Heidegger supo cuestionar en su carácter teleológico ${ }^{13}$; de otro lado, la misma división entre antigüedad y modernidad, o entre época clásica y moderna, no sólo por la posibilidad de circunscribir de modo claro y distinto cada momento, sino porque esto genera un modo de trabajo conceptual que precisa significados desde la contextualización. Esta perspectiva no busca desconocer los cambios o variaciones conceptuales, sino todo lo contrario, mostrar cómo esas variaciones son reducidas por esquemas históricos ${ }^{14}$ :

\footnotetext{
Volver a poner en cuestión no sólo ese afán de periodización que adopta semejantes formas (una modernidad que no sabemos dónde comienza ni dónde acaba, una edad clásica cuyos efectos todavía son perceptibles, una antigüedad griega cuyos conceptos están más vivos y sobrevivientes que nunca, ese presunto «acontecimiento decisivo de la modernidad» o «acontecimiento fundador de la modernidad» que no hace sino poner de manifiesto lo inmemorial, etc.), [volver a poner en cuestión no sólo ese afán de periodización que adopta semejantes formas] no es reducir la aconteci-
}

12. Revel, J.: Foucault et Derrida. París: Bayard, 2014 y Campillo, A.: "Foucault-Derrida: historia de un debate sobre la historia" en Revista Daimon N 11, 1995.

13. Derrida, J.: "Envío" en La deconstrucción en las fronteras de la filosofía, Madrid: Paidós, 1997.

14. Escribe Derrida: «Eso no quiere decir -lo sugerí la última vez e insisto hoy en ello-, eso no quiere decir, naturalmente, que Aristóteles ya hubiese previsto, pensado, comprendido, analizado todas las figuras de lo zoopolítico o de lo biopolítico de hoy: sería absurdo pensarlo. Pero, en cuanto a la estructura biopolítica o zoopolítica, Aristóteles la nombra; ésta ya está ahí, y ahí es donde se abre el debate». Derrida, J.: Seminario La bestia y el soberano I, Buenos Aires: Manantial, 2010 p. 405.

Thémata. Revista de Filosofía $\mathrm{N}^{\circ} 56$ (2017) pp.: 285-303. 
bilidad o la singularidad del acontecimiento. Al contrario. Tengo más bien la tentación de pensar que dicha singularidad del acontecimiento es tanto más irreductible y desconcertante, como debe serlo, cuanto que se renuncia a esa historia lineal que sigue siendo -a pesar de todas las protestas que, sin duda, ellos elevarían contra esta imagen- la tentación común de Foucault y de Agamben (la modernidad que viene después de la edad clásica, las épistêmê que se suceden y se tornan caducas unas a otras, Agamben que viene después de Aristóteles, etc.), que se renuncia a esa historia lineal, a la idea de acontecimiento decisivo y fundador ${ }^{15}$.

\section{El entramado de soberanía y vida}

Como otras perspectivas contemporáneas, en su distanciamiento con la epocalización foucaultiana, J. Derrida cuestiona la existencia de un límite simple entre soberanía y biopolítica. Y esto no sólo porque cada vez que se busca precisar el rasgo que hace de la soberanía algo moderno se vuelve sobre motivos clásicos, sino justamente porque algo como "la» soberanía no existe, sino que hay formas diferentes y antagónicas de soberanías. Por ello, indica J. Derrida, siempre se trata de un "fantasma" de soberanía, o si se quiere de su constitución como ficción narrativa ${ }^{16}$. Luego porque la vida, un modo de la vida, constituye la misma soberanía: existe una relación inmanente entre poder y vida (lo que supone cuestionar un esquema donde el poder tiene una relación exterior con la vida, sea la que fuere). Me detengo en dos movimientos privilegiados.

Por un lado, Aristóteles. J. Derrida insiste contra cierta doxa historicista que existe un pensamiento de la soberanía ya en el pensamiento clásico. De hecho, para definir "soberanía» elige a Aristóteles como fuente privilegiada: «Ésta es la definición ontológica de la soberanía, es decir, que es mejor -puesto que se busca vivir bien (eu zên) - vivir en autarquía, es decir, teniendo en nosotros mismos nuestro principio, teniendo en nosotros mismos nuestro comienzo y nuestro mandato» ${ }^{17}$. Desde la definición de so-

\section{Derrida, J.: Seminario La bestia y el soberano I cit., p. 387.}

16. Señala Derrida: «La soberanía es esa ficción narrativa o ese efecto de representación. La soberanía saca todo su poder, toda su potencia, es decir, toda su omnipotencia, de este efecto de simulacro, de este efecto de ficción o de representación que le es inherente y congénito, co-originario en cierto modo». Derrida, J.: Seminario La bestia y el soberano I cit., p. 341.

17. Derrida, J.: Seminario La bestia y el soberano I cit., p. 402. En Canallas, Derrida acentúa la definición de soberanía desde la ipseidad: "Entenderé pues tanto el si mismo, el "mismo" de "si" (es decir, el mismo, meisme, que viene de metipse), como el poder, la potencia, la soberanía, lo posible implicado en todo "yo puedo", el pse de ipse (ipsissimus) que remite siempre -Benveniste lo muestra perfectamente-, a través de complicados relevos, a la posesión, a la propiedad, al poder, a la autoridad del señor, del soberano y, casi siempre, del anfitrión (hospites), del senor de la casa o del marido. De manera que, por si solo -como, por lo demás, autos en griego-, ipse puede traducir (ipse es autos, y la traducción latina del "conócete a ti mismo",

Thémata. Revista de Filosofía $\mathrm{N}^{\circ} 56$ (2017) pp.: 285-303. 
beranía como algo que tiene el fin en sí mismo, J. Derrida muestra cómo esa definición ya implica una cierta relación con la vida. En este sentido, acuerda con G. Agamben cuando muestra el nexo constitutivo para Occidente entre vida y política, pero cuestiona que sea posible distinguir claramente en Aristóteles entre zoe y bios (que Agamben precisa recurriendo a una distinción entre atributo esencial y diferencia específica que no se sostiene $\left.{ }^{18}\right)$ :

[...] justamente, lo que nos dice Aristóteles, y ahí es donde esta distinción entre ambas atribuciones no funciona, es que el hombre es ese ser vivo que está atrapado por la política: es un ser vivo político, esencialmente. Dicho de otro modo, es zoo-político, ésa es su definición esencial, es lo que le es propio, idion; lo que es propio del hombre es la política; lo que es propio de ese ser vivo que es el hombre es la política, por lo tanto, el hombre es inmediatamente zoo-político, en su vida misma, y la distinción entre bio-política y zoo-política no funciona aquí en absoluto ${ }^{19}$.

Por otro lado, Hobbes. Derrida muestra que, contra la distinción recurrente entre una lógica de la soberanía y una lógica biopolítica (o disciplinaria, o gubernamental), existe un entramado inmanente entre soberanía y vida. Incluso se puede radicalizar esta lectura indicando que no es sino el problema de la vida el centro de la preocupación de la lógica hobbesiana de la soberanía. La fundamentación racional -la legitimaciónde la soberanía parte de la ficción teórica según la cual lo infinito del deseo conduce de modo inevitable al conflicto, a una guerra en la que justamente el problema es la muerte, esto es, la imposibilidad de la vida. Así se reconoce como derecho natural la auto-conservación de la vida y la utilización de todos los medios para ello. Por lo que la cesión de derechos para la constitución del soberano no tiene sino como fin proteger la vida, y por ende soberano no es sólo quien garantiza la vida sino quien hace posible su desarrollo. Derrida lee a Hobbes para mostrar de qué modo la soberanía surge como una prótesis artificial cuya finalidad esencial es una protección fundada en la indivisibilidad de la soberanía. La soberanía garantiza la

de gnothi seauton, es efectivamente cognosce te ipsum), ipse designa el sí mismo como señor en masculino: el padre, el marido, el hijo o el hermano, el propietario, el poseedor, el senor, también el soberano». Derrida, J.: Canallas cit., p. 21.

18. Regazzoni, S.: "Biopolítica y deconstrucción" en Biset, E. y Penchaszadeh, A. P.: Derrida político. Buenos Aires: Colihue, 2013.

19. Derrida, J.: Seminario La bestia y el soberano I cit., p. 405.

Thémata. Revista de Filosofía $\mathrm{N}^{\circ} 56$ (2017) pp.: 285-303. 
vida de los súbditos inmunizándola ${ }^{20}$. Esto significa que la soberanía requiere para su funcionamiento una captación de la vida:

Es como una prótesis gigantesca destinada a amplificar, objetivándolo fuera del hombre natural, el poder del ser vivo, del hombre vivo al que protege, sirve, pero como una máquina muerta, incluso una máquina de muerte, una máquina que no es sino la máscara del ser vivo, como una máquina de muerte puede servir al ser vivo. Pero esa máquina estatal y protética, digamos protestatal, esa protestatalidad debe a la vez prolongar, remedar, imitar, reproducir incluso hasta en el mínimo detalle al ser vivo que la produce ${ }^{21}$.

Nada más alejado de la definición de soberanía exclusivamente como decisión sobre la muerte, desde que el mismo funcionamiento de la soberanía funda la conservación y expansión de la vida en una ley legitimada en el contrato. Esto abre una vía de indagación que muestra no sólo la centralidad de la vida en la estructura inmunitaria de la soberanía, sino la lógica soberana que atraviesa la biopolítica, en tanto su misma posibilidad como decisión sobre la vida, administración de las poblaciones, supone un modo soberano de ejercicio del poder.

Las lecturas de Aristóteles y Hobbes -entre otros- sirven para mostrar cómo la búsqueda de la singularidad de la biopolítica en oposición a la soberanía termina por impedir pensar precisamente cómo funciona. Lo que otorga una precisa indicación para el pensamiento político actual: las retóricas del abandono de la soberanía - o de la estatalidad- sea de modo analítico o propositivo, conllevan una serie de problemas ${ }^{22}$. Una mirada atenta no debe dejar de indagar por los modos de contaminación, de una diferencia que constituye un entramado, que cuestionan un abandono de un pensamiento del modo en que opera la soberanía y de las estrategias

20. Cf. Esposito, R.: Inmunitas. Buenos Aires: Amorrortu, 2005.

21. Derrida, J.: Seminario La bestia y el soberano I cit., p. 49. Escribe Simone Regazzoni: «La soberanía es entonces el alma, el principio vital que amplifica la vida de los vivientes que protege: pero como una máquina de muerte al servicio del viviente, una máquina de muerte para indemnizar al viviente. Esto es lo que escapa a cierto paradigma biopolítico: la lógica de la indemnización sacrificial de la soberanía, en la cual la muerte trabaja al servicio de la vida -y así un pensamiento diferente del enigma de lo político como enigma de que se llama vida, más allá de la imaginaria oposición de bios y zoe». Regazzoni, S.: Derrida. Biopolitica e democracia, Genova: Il Melangolo, 2012 p. 28.

22. Esta observación se orienta también por una serie de lecturas de M. Foucault que cuestionan su lectura en términos anti-estatalistas. Cf. Jessop, B.: "Another Foucault effect? Foucault on Governmentality and Statecraft", en Bröckling, U., Krasmann, S., Lemke, T. (eds.): Governmentality: Current Issues and Future Challenges, Nueva York: Routledge, 2010 y García, H.: "Foucault y el Estado" en Biset, E. y Farrán, R.: Estado. Perspectivas posfundacionales, Buenos Aires: Prometeo, 2017.

Thémata. Revista de Filosofía $\mathrm{N}^{\circ} 56$ (2017) pp.: 285-303. 
políticas que pueden dirigirse a ello. Por ello, para J. Derrida se trata de producir un pensamiento que atiende a los modos en que se da ese entramado que imposibilita una delimitación unívoca de los conceptos. Y esto sucede en las dos direcciones precisadas. Primero, como indiqué, se pregunta por la consideración de la soberanía como algo único e indivisible, señalando que se trata de pensar siempre en la partición de la misma. Esta equivocidad hace que su límite con un afuera no sea simple, no hay un contrario de la soberanía:

[...] no hay un contrario de la soberanía, aunque haya algo distinto de la soberanía. Incluso en política (y queda la cuestión de saber si el concepto de soberanía es político de arriba abajo), incluso en política, la elección no se da entre soberanía y no-soberanía sino entre varias formas de repartos, de particiones, de divisiones, de condiciones que vienen a encentar una soberanía siempre supuestamente indivisible e incondicional ${ }^{23}$.

Segundo, lo mismo sucede con el concepto de vida. La pregunta es qué define lo vivo de la vida, lo que "ahora» se mantiene con vida, es decir, «[...] la pregunta "¿qué es lo vivo de la vida?" retiene su aliento ante la legitimidad problemática de una sumisión de la cuestión de la vida a una cuestión del ser, de la vida al ser» ${ }^{24}$. Se trata de pensar la equivocidad del ser vivo, concebido muchas veces desde una lógica de la espontaneidad automotriz regulada por el presente, esto es, una definición de vida como relación consigo, apropiación, o pura potencia de autoafección. No es sino una vida sin resto, sin contaminación, pura presencia. Un concepto de vida como pura potencia de auto-afección no sólo es un imposible sino que genera una ficción teórica con efectos político ${ }^{25}$.

Para decirlo de otro modo, si la vida se encuentra atravesada por restos, constituirla como puro presente conlleva una lógica sacrificial de todo aquello que la contamina ${ }^{26}$. Esto ha sido desarrollado a lo largo de diversos escritos de Derrida bajo la noción de «auto-inmunidad»:

23. Derrida, J.: Seminario La Bestia y el soberano I cit., p. 104.

24. Derrida, J.: Seminario La Bestia y el soberano I cit., p. 260.

25. De hecho es posible indagar, como señala Davide Tarizzo, si la vida (como invención reciente) no remite a una lógica del sí-mismo, del autós: «[...] así como la voluntad obedece sólo a sí misma, según Kant, y tal es el sentido auténtico del "imperativo categórico", al mismo tiempo la vida debería obedecer sólo a sí misma, según Darwin, y tal debería ser el sentido auténtico de la "selección natural"». Tarizzo, D.: La vita, un’invenzione recente, Bari-Roma: Laterza, 2010 p. 107.

26. Indudablemente los aportes de J. Derrida a la biopolítica analizando su lógica sacrificial deben atender a su indagación sobre la animalidad. La no-pureza de lo vivo, como puro

Thémata. Revista de Filosofía $\mathrm{N}^{\circ} 56$ (2017) pp.: 285-303. 
Segrega su propio antídoto pero también su propio poder de autoinmunidad. Nos encontramos aquí en un espacio en donde toda autoprotección de lo indemne, de lo san(t)o y salvo, de lo sagrado (heilig, holy) debe protegerse contra su propia protección, su propia policía, su propio poder de rechazo, lo suyo sin más, es decir, contra su propia inmunidad. Esta aterradora pero fatídica lógica de la autoinmunidad de lo indemne ${ }^{27}$.

En esta lógica la misma protección de la vida, y la soberanía como protección que garantiza la expansión de la vida, se repliega sobre sí destruyendo sus propias barreras inmunitarias, es decir, exponiéndose a su propia destrucción por la intromisión del mal externo: «[...] un principio de autodestrucción sacrificial que arruina el principio de protección de sí (del mantenimiento de la integridad intacta de uno mismo), y ello con vistas a alguna super-vivencia invisible y espectralı ${ }^{28}$.

\section{Una economía de la vida y la muerte}

Deconstruir la biopolítica desde la equivocidad de las nociones de soberanía y vida, también abre a otros modos de pensar las estrategias políticas contemporáneas. Posiblemente un indicio irreductible al respecto sea el siguiente: la hegemonía de una retórica de la resistencia pensada como contrapoder frente a la biopolítica. Sea en la atención a las contra-conductas, a las prácticas de libertad o al cuidado de sí, la pregunta que me interesa formular es qué significa pensar todo esto en términos de

presente, también lleva a cuestionar las diferencias en la vida, es decir, a preguntar cómo diferentes formas de humanismo tratan de fijar lo propiamente humano de la vida. Esta preocupación recorre los últimos escritos de J. Derrida. Cf. Derrida, J.: El animal que luego estoy si(gui)endo. Madrid: Trotta, 2008; Wolfe, C.: Animal Rites. Chicago: University of Chicago Press, 2003; Giorgi, G.: Formas communes, Buenos Aires: Eterna Cadencia, 2014; Haraway, D., Simians, Cyborgs, and Women. Nueva York: Routledge, 1991 y Fadini, U., Negri, T. y Wolfe, C., Desiderio del mostro. Dal circo al laboratorio alla politica. Roma: Manifestolibri, 2001.

27. Derrida, J.: "Fe y saber" en La religión, Buenos Aires: De la Flor, 1997. Cf. Naas, M.: "One Nation... Indivisible: Of Autoimmunity, Democracy, and the Nation-State" en Derrida from now on, New York: Fordham University Press, 2008.

28. Derrida, J.: "Fe y saber" cit., p. 83 «[...] la ley dividida, el double bind, y asimismo el doble foco, la elipse/elipsis o la duplicidad originaria de la religión, es que la ley de lo indemne, la salvación de lo salvo, el respeto púdico de lo que es sacrosanto (heilig, holy), exige y excluye a la vez el sacrificio, a saber, la indemnización de lo indemne, el precio de la inmunidad. Por consiguiente, la autoinmunización y el sacrificio del sacrificio". Derrida, J.: "Fe y saber" cit., p. 84. Indudablemente la reflexión sobre lo espectral en J. Derrida es un lugar privilegiado para pensar "la vida la muerte" en sus dimensiones políticas. Cf. Derrida, J.: Espectros de Marx. Madrid: Trotta, 1998 y Ludueña, F.: La comunidad de los espectros. Buenos Aires: Miño \& Dávila, 2010.

Thémata. Revista de Filosofía N56 (2017) pp.: 285-303. 
resistencia. (De modo radical me gustaría preguntar si un pensamiento de la oposición entre poder y resistencia no termina por asumir, de modo crítico, una perspectiva liberal; para decirlo de otro modo, la cuestión no pasa por reformular de modo crítico un pensamiento del poder y la resistencia, sino un pensamiento político que exceda esa gramática). La cuestión a pensar es entonces esta resistencia que al asumir la imposibilidad de un exterior simple del poder, asume la necesidad de un contra-poder basado en la misma vida. Sucede que en ciertos casos cuando la vida se piensa como lugar de resistencia, en términos de singularidad impersonal, línea de fuga, devenir animal, etc., se reinventa una noción de vida como potencia plena e inmediata. En otros términos, una vida sin diferencia, sin resto, una vida saturada en una lógica del goce absoluto. Por ello, J. Derrida se enfrenta a cierta deriva de una biopolítica afirmativa como pura potencia. Aún más, esta deriva termina haciendo de la vida una pulsión de poder que reinscribe una lógica de la inmunidad, esto es, la circularidad de la vida como goce es precisamente una pulsión soberana. Contra ello, J. Derrida va a pensar la vida justamente como diferencia, es decir, en función de su límite divisible con la muerte. El problema está en aquellas posiciones que mantienen una división analítica entre vida y muerte, pues se trata de pensar el modo en que vida y muerte son inescindibles.

No resulta menor que recurrentemente cuando J. Derrida discute a M. Foucault, lo hace a través de una lectura de S. Freud. Los aspectos a pensar en esta lectura cruzada son múltiples: el estatuto de lo analítico, el lugar del psicoanálisis en la historia de la locura, la posibilidad de escindir vida y muerte. Para lo que aquí interesa me voy a detener en aquellos lugares donde J. Derrida aborda el último aspecto, donde piensa la pulsión para mostrar que no existe una oposición simétrica entre pulsión de placer y pulsión de muerte, sino un mismo circuito pulsional:

Pero mi «hipótesis» de lectura, de este texto y de algunos otros, intentaría destramar lo que se trama aquí entre el primer principio y lo que aparece como su otro, a saber el principio de realidad como $s u$ otro, la pulsión de muerte como su otro: una estructura de alteración sin oposición. Lo que parece hacer entonces más continua, más inmanente, más natural también la pertenencia sin interioridad de la muerte al placer es también lo que la hace más escandalosa a los ojos de una dialéctica o de una lógica de la oposición ${ }^{29}$.

De hecho, se trata de un Seminario que J. Derrida dedica a S. Freud bajo el título «La vida la muerte», lo que indica precisamente que no

29. Derrida, J.: "Especular - sobre Freud", en La tarjeta postal de Sócrates a Freud y más allá, Buenos Aires: Siglo XXI, 2001 p. 273.

Thémata. Revista de Filosofía №56 (2017) pp.: 285-303. 
existe una oposición entre vida y muerte, o si se quiere que la muerte se inscribe como una ley interna de la vida (y no como un accidente, un límite, un fin). Lo que también puede ser definido como una economía pulsional. He allí la cuestión a pensar, una economía entre vida y muerte que no las opone de modo simple, sino que muestra su atravesamiento.

Y así se trata de pensar diferentes economías de la-vida-la-muerte. De un lado, uno de los modos de pensar esa diferencia es la apropiación, o una economía de la apropiación vital, o una lógica circular de la vida que se apropia de la muerte sin resto para potenciarse:

Más allá de todas las oposiciones, sin identificación o síntesis posible, se trata sin duda de una economía de la muerte, de una ley de lo propio (oikos, oikonomia) que gobierna el rodeo y busca incansablemente el acontecimiento propio, su propia propiación (Ereignis) más bien que la vida y la muerte, la vida o la muerte. El alargamiento o el abreviamiento del rodeo estarían al servicio de esta ley propiamente económica o ecológica de uno mismo como propio, de la autoafección automóvil del fort:da ${ }^{30}$.

Esta lógica de la apropiación no es sino un modo de delimitar la relación entre vida y muerte a partir de una definición del sujeto como auto-afección ${ }^{31}$. De otro lado, una economía de la expropiación finita, o de una lógica que no sólo interrumpe la circularidad sino que trabaja con restos: «La estructura exapropiadora es pues irreductible e indescomponible. Da el mando a la represión. Impide siempre a la reapropiación volverse a cerrar o cumplirse en círculo, círculo económico o círculo de familia. Ningún progreso, ninguna progresividad del hombre ${ }^{32}$. Con ello, J. Derrida se refiere a un trazado de la-vida-la-muerte que no se regula por una teleología de la reapropiación, esto es, lo que cuenta es el ritmo de la diferencia y la andadura. No resulta menor que J. Derrida termine esta lectura de Freud con una referencia al «ritmo», que no es sino un modo de pensar la diferencia más allá de la oposición o de la dialéctica, es decir, la muerte como ley interna de la vida que excede lo propio y el dominio del sujeto.

Esta referencia a S. Freud que J. Derrida reitera leyendo a F. Nietzsche, a M. Heidegger, a M. Blanchot, no es sólo una indicación sobre cómo la noción de vida, incluso en ciertos planteos contemporáneos, es tematizada como presente vivo, potencia de autoafección, pura presencia, sino que se inscribe en un modo de concebir el pensamiento político contemporáneo. Si destaqué ya que uno de los desafíos críticos es cómo pensar de modo más preciso la relación entre vida y soberanía, excediendo la epocalización, en

30. Ibid., p. 338.

31. Cf. Biset, E.: "Sujeto y metafísica" en AA.VV., Sujeto. Una categoría en disputa cit.

32. Derrida, J.: "Especular - sobre Freud" cit., p. 341.

Thémata. Revista de Filosofía $\mathrm{N}^{\circ} 56$ (2017) pp.: 285-303. 
este caso se trata de mostrar la distancia entre una política de la finitud y una política de la potencia ${ }^{33}$. Y por ello el psicoanálisis desempeña un papel central, no sólo dislocando la oposición vida-muerte (y haciendo, como destaca J. Derrida en otros textos, de la vida cada vez sobre-vida ${ }^{34}$ ), sino destituyendo cualquier política de la pura afirmatividad. Se trata, para decirlo brevemente, de un pensamiento político que al asumir la finitud, contra las reinvenciones del vitalismo contemporáneo, piensa la política como negociación:

Si la pulsión de poder o la pulsión de crueldad es irreductible, más vieja, más antigua, que los principios (de placer o de realidad, que son en el fondo el mismo, como preferiría decir: el mismo en diferancia), entonces ninguna política podrá erradicarla. Sólo podrá domesticarla, diferirla, aprender a negociar, a transigir, indirectamente pero sin ilusión, con ella, y es esta indirección, esta vuelta diferante, este sistema de relevo y de plazo diferenciales, la que dictará la política optimista y a la vez pesimista, valientemente desengañada ${ }^{35}$.

He aquí una nota central: no sólo se trata de otro concepto de diferencia respecto de M. Foucault, sino de señalar que la apuesta política pasa por esa diferencia, es decir, de una transacción diferencial, de una

33. Esto abre a una serie de discusiones contemporáneas sobre la relación entre muerte y política. Conceptos como tanatopolítica o necropolítica se dirigen a ello. Cf. Biset, E.: "Tanatopolítica”, Revista Nombres № 26, 2012. Asimismo: Mbembe, A.: Necropolítica. Madrid: Melusina, 2011 y Ojakangas, M.: "Impossible Dialogue on Bio-power. Agamben and Foucault", Foucault Studies 2, 2005.

34. Derrida, J.: "Sobrevivir" en Deconstrucción y crítica, México: Siglo XXI, 2003. Escribe en este texto Derrida: "Aquí la cosa es "horrenda" porque en su mismo no suceder, le sucede (sobreviene) al "Ven"; en su nada de nada resulta un proceso que no puede ser decidido, al no ser ni vida ni muerte, sino más bien supervivencia; es el mismo proceso que pertenece, sin pertenecer, al proceso de la vida y de la muerte. Sobrevivir no es lo opuesto de vivir y tampoco lo mismo que vivir. La relación es distinta, difiere de ser idéntica, difiere de la distinción de las diferencias». Derrida, J.: "Sobrevivir" cit., p. 133. En otro lugar: «Esa supervivencia es mi vida desbordada por ella, y el nombre de mi muerte, de mi vida muerta, tal el nombre de mi padre, y también mi patronímico». Derrida, J.: Otobiografías, Buenos Aires: Amorrortu, 2009, p. 48.

35. Derrida, J.: Estados de ánimo del psicoanálisis, Buenos Aires: Paidós, 2001, p. 35. Incluso es posible preguntar, como lo realiza L. Odello, si no es desde una lógica de la pulsión que se comprende la referencia a "Walten» como hiper-soberanía en los textos tardíos de J. Derrida. Cf. Odello, L.: "Walten ou l'hyper-souveraineté", en Cohen-Levinas, D. y Michaud, G. (comps.): Appels de Jacques Derrida, Paris: Hermann, 2014 y Naas, M.: "«World, finitude, solitude»: Derrida's Walten", en The end of the world and others teacheable moments, Fordham University Press, 2015.

Thémata. Revista de Filosofía №56 (2017) pp.: 285-303. 
economía de la différance, que trabaja de modo indirecto (frente a la supuesta inmediatez de la vida).

\section{Cierre: la doble estrategia}

Los elementos presentados, en su doble dimensión, constituyen una deconstrucción de la biopolítica. Atendiendo, ante todo, a que esto no implica negar la pertinencia de aquello que vienen a mostrar los trabajos sobre la biopolítica contemporánea, sino indagar sobre algunos supuestos teóricos que la constituyen. Deconstrucción de la biopolítica significa mostrar tres cosas: primero, que la noción de vida no es simple, sino que existen disputas en torno a su sentido, a lo vivo de la vida, por lo que se trata de pensar la vida en plural a partir de un límite divisible respecto de sus alteridades; segundo, que la noción de política tampoco es simple, no sólo porque no existe un concepto adecuado de lo político, sino porque Derrida piensa en una estructura donde es precisamente la ausencia de un significado unívoco lo que da lugar a intentos precarios por definirla (p.e., si se entiende política como soberanía, insiste en que no existe «la» soberanía sino diferentes figuras desde las que se busca fijar su sentido); tercero, porque dada la equivocidad inscripta en las nociones de vida y política es necesario pensar en cada caso cómo se da una transacción diferencial entre vida y política. En otros términos, una deconstrucción de la biopolítica supone una complejización de la misma desde el momento en que se problematiza las definiciones de vida, política y del nexo que las articula.

Como he intentado mostrar, estos supuestos atraviesan el modo de definir la biopolítica pero también las estrategias de resistencia que se diseñan. En este sentido, no se trata de una discusión que pueda ser reducida a un trabajo textual de J. Derrida, sino a indagar cómo se termina por configurar un pensamiento político que oblitera una serie de diferencias que hacen de la biopolítica algo mucho más difícil de circunscribir de lo que aparece en ciertas taxonomías. Se trata de pensar la articulación entre soberanía y vida más allá de la doxa biopolítica organizada epocalmente y así abrir a una política de la finitud como trabajo indirecto, mediación, economía de la diferencia. Si la insistencia en el término "economía» se encuentra a lo largo de los textos de Derrida, aquí resulta significativo para precisar algunas conclusiones finales. Puesto que se trata de dos modos económicos del pensamiento político: o bien una economía restringida or-

Thémata. Revista de Filosofía N56 (2017) pp.: 285-303. 
ganizada en torno a la inmediatez o la reapropiación, o bien una economía general, que se tensa con lo an-económico, como negociación diferencial ${ }^{36}$.

Esta negociación diferencial, o si se quiere, entender la negociación como un trabajo de la diferencia, tiene consecuencias en las prácticas teóricas y en los posicionamientos políticos. En este sentido, deconstruir una relación entre vida y soberanía trazada desde un límite indivisible da lugar a un pensamiento que aborda la cuestión de la soberanía desde una doble estrategia: por un lado, trabaja sobre su pliegue interno, repliega la soberanía sobre sí para mostrar sus límites (indicando a su vez que un ataque frontal a la soberanía estatal puede suponer una concesión a la lógica del capital cuya expansión universal encuentra en la figura del Estado muchas veces un límite); por otro lado, trabaja sobre su pliegue externo, mostrando aquello que permanece como límite estructural de una lógica de la soberanía. Sin embargo, frente a aquellas posiciones que entienden que la deconstrucción es una apuesta simple por la deconstrucción de la soberanía, me interesa indicar que esa doble estrategia no puede entenderse como algo escindido. Para decirlo de otro modo, que sólo una transacción diferencial al interior de la soberanía posibilita su exceso ${ }^{37}$. Quisiera, para finalizar, retomar dos citas de Derrida:

Primera cita:

Si casi siempre lo que se juega tanto en la política como en todas partes en donde se ejerce una pulsión de poder (Bemächtigungstrieb, dice Freud, antes o más allá de las otras pulsiones y de la pulsión de muerte), una pulsión de poder que ordena incluso la pulsión de ver y de saber, la pulsión escópica y epistemofílica, [si casi siempre lo que se juega tanto en la política como en todas partes en donde se ejerce una pulsión de poder] es no ya una alternativa entre soberanía y no-soberanía sino una lucha por la soberanía, unos traspasos y unos desplazamientos, incluso unas divisiones de soberanía, aquello de lo que hay que partir ya no es del concepto puro de soberanía sino de unos conceptos como pulsión, traspaso, transición, traducción, paso, división. Es decir, asimismo herencia, transmisión y, con la división, la distribución, por consiguiente, la economía de la soberanía. La economía es una división distributiva no sólo a causa del oikos cuya ley ella es, sino porque la ley (nomos, nemein) significa también la división ${ }^{38}$

36. Distinción de economía que Derrida trabaja en torno a Georges Bataille. Derrida, J.: "De la economía restringida a la economía general", en La escritura y la diferencia, Madrid: Anthropos, 1989. Cf. Biset, E.: "Economías", en Violencia, justicia y política. Córdoba: Eduvim, 2012.

37. Cf. Biset, E.: "Derrida y el Estado" en Biset, E. y Farrán, R. (eds.): Estado. Perspectivas posfundacionales cit.

38. Derrida, J.: Seminario La Bestia y el soberano I cit., p. 341.

Thémata. Revista de Filosofía $\mathrm{N}^{\circ} 56$ (2017) pp.: 285-303. 


\section{Segunda cita:}

Porque de hecho, como bien sabemos, en todas partes en donde, hoy más que nunca pero desde ya tanto tiempo, en todas partes en donde creemos hacer frente a problemas de soberanía, como si tuviésemos que elegir entre el soberanismo y el anti-soberanismo -ya parezca suceder eso en unos sofisticados debates de teoría política o jurídico-políticos o en la retórica del café del comercio o de los salones de la agricultura-, pues bien, la cuestión no es la de la soberanía o de la no-soberanía sino la de las modalidades del traspaso y de la división de la soberanía así llamada indivisible - llamada y supuestamente indivisible, pero que siempre es divisible ${ }^{39}$.

Con estas citas me interesa volver sobre lo señalado al comenzar, puesto que entiendo que se trata de producir otro entramado entre diversos lenguajes políticos. Con ello me refiero a conjugar lo arcaico del poder con sus modos contemporáneos, y así atender a lo que acontece desde un pensamiento que piensa la diferencia como sedimentación que se desplaza constantemente. Si aquí se juega un distanciamiento respecto de la epocalización como cifra de comprensión de la novedad, o de las lógicas políticas de la contemporaneidad, también se da lugar a otras estrategias políticas. O para decirlo de otro modo, se trata de combinar una estrategia de escritura teórica, pero también una estrategia política, que supone dos aspectos. De un lado, una idea de negociación irreductible, o si se quiere la imposibilidad de un afuera o más allá simple. De otro lado, asumir que esa negociación excede la forma-resistencia, puesto que no se trata de resistir al poder, sino de poder contra poder, de lucha, de una guerra infinita, que trata cada vez de dar lugar a la justicia. Esto implica, vale destacar, también una lectura específica de J. Derrida. No sólo porque resulta necesario indagar la singularidad de la soberanía que puede perderse en su homologación con el poder sin más, sino en tanto me interesa desplazar aquellas posiciones que hacen de la justicia una incondicionalidad opuesta a la soberanía ${ }^{40}$. Y así, entonces, una política de la transacción diferencial

\section{Derrida, J.: Seminario La Bestia y el soberano I cit. p. 341.}

40. Algo que, es necesario indicarlo, parece ser lo que prima en los mismos textos de Derrida: «Se trataría pues, ésta fue al menos la hipótesis o el argumento que someto a su discusión, de cierta indisociabilidad entre, por un lado, la exigencia de soberanía en general (...) y, por otro lado, la exigencia incondicional de lo incondicionado (anhypotheton, unbedingt, incondicionado). [...] Me atreveré, pues, a ir más lejos. Llevaré la hipérbole más allá de la hipérbole. No se trataría sólo de disociar pulsión de soberanía y exigencia de incondicionalidad como dos términos simétricamente asociados, sino de cuestionar, de criticar, de deconstruir, si quieren, la una en nombre de la otra, la soberanía en nombre de la incondicionalidad». Derrida, J.: Canallas cit., p. 169. Y en otro lugar: "Ahora bien, afirmaré que hay, es necesario que haya,

Thémata. Revista de Filosofía $\mathrm{N}^{\circ} 56$ (2017) pp.: 285-303. 
-de la negociación- sólo puede ser una estrategia singular que trabaja sobre la misma divisibilidad interna y externa que se trama en un orden conceptual o un entramado institucional.

a referencia a lo incondicional, un incondicional sin soberanía y por lo tanto sin crueldad, cosa sin duda muy difícil de pensar. [...] Se refiere a una vida, ciertamente, pero a otra vida que la de la economía de lo posible, una vida im-posible sin duda, una supervivencia, y no simbolizable, si no la única que valga ser vivida, sin coartada, de una vez por todas, la única a partir de la cual (digo bien a partir de la cual) un pensamiento de la vida es posible. De una vida que todavía valga ser vivida, de una vez por todas». Derrida, J.: Estados de ánimo del psicoanálisis cit., p. 76. 

NOTAS 
